\title{
Long-Term Outcomes Following Thermal Ablation of Benign Thyroid Nodules as an Alternative to Surgery: The Importance of Controlling Regrowth (Endocrinol Metab 2019;34:117-23, Jung Suk Sim et al.)
}

\author{
Jung Suk Sim ${ }^{1}$, Jung Hwan Baek ${ }^{2}$
}

${ }^{1}$ Department of Radiology, Withsim Clinic, Seongnam; ${ }^{2}$ Department of Radiology and the Research Institute of Radiology, Asan Medical Center, University of Ulsan College of Medicine, Seoul, Korea

We thank Dr. Kim for his pertinent comments regarding our article [1]. As Dr. Kim commented, a substantial proportion of thermally ablated nodules can regrow, especially when their initial volume is large and they are followed for a longer period of time. We can and should inform patients that the treatment may not end with a single session of ablation and that multiple sessions may be necessary, so that patients can make an appropriate choice between ablation and surgery. Regarding this issue, several factors should be considered to predict how many sessions will be needed. It is known that factors such as the initial nodule volume, the vascularity and solidity of the nodule, and its proximity to dangerous structures are related to the number of sessions of ablation [2]. We agree with Dr. Kim's suggestion that the previous growth rate of the nodule before ablation can be considered as a factor relevant for predicting treatment response and the number of sessions; however, to our best knowledge, we could not find previous research dealing with that topic.

Dr. Kim also suggested that some ablated nodules with rapid regrowth might be malignant. These concerns involve two separate concepts: false-negative biopsy results before radiofrequency ablation (RFA) and RFA-induced malignant change of benign nodules. First, false-negative biopsy results before RFA

Received: 18 August 2019, Accepted: 27 August 2019

Corresponding author: Jung Hwan Baek

Department of Radiology and the Research Institute of Radiology, Asan Medical Center, University of Ulsan College of Medicine, 88 Olympic-ro 43-gil, Songpagu, Seoul 05505, Korea

Tel: +82-2-3010-4348, Fax: +82-2-476-0090, E-mail: radbaek@naver.com can be minimized by conducting two biopsies before RFA, as recommended by the Korean RFA guideline [2,3]. Regarding the second concept underlying this concern, Ha et al. [4] evaluated pathologic findings of core-needle biopsy (CNB) specimens for 16 re-growing nodules after RFA. No atypical cells or neoplastic transformations were detected in the undertreated peripheral portion of treated re-growing benign nodules on the CNB specimens. In contrast, Dobrinja et al. [5] performed RFA for six nodules with indeterminate biopsy results (Bethesda categories 3 and 4). Two of the six nodules showed regrowth and surgery was performed. Their final pathologic results were minimally invasive follicular carcinoma and follicular neoplasm of indeterminate malignant behavior. Therefore, they did not recommend RFA as a first-line therapy for thyroid nodules with indeterminate results. Most recently, Kim et al. [6] reported that according to published research, the tumor volume doubling time could not predict malignancy in thyroid nodules cytologically diagnosed as follicular neoplasms.

Dr. Kim's last concern was the application of RFA for follicular variant papillary thyroid carcinoma and/or follicular carcinoma. Could RFA yield a similar effect to that of partial diagnostic thyroid surgery, with respect to the prevention of future metas-

Copyright $\odot 2019$ Korean Endocrine Society

This is an Open Access article distributed under the terms of the Creative Commons Attribution Non-Commercial License (http://creativecommons.org/ licenses/by-nc/4.0/) which permits unrestricted non-commercial use, distribution, and reproduction in any medium, provided the original work is properly cited. 
tasis? One pilot study about this concern has been published. Ha et al. [4] reported 5-year follow-up results of RFA for small $(<2$ $\mathrm{cm})$ follicular neoplasms. Their results showed that RFA represents an effective local tumor control method without distant metastasis for small $(<2 \mathrm{~cm})$ follicular neoplasms. However, a long-term follow-up study with a larger population is necessary to clarify this issue.

Dr. Kim's comments are valuable for understanding our results. We deeply appreciate Dr. Kim's comments, which we believe have enriched our study.

\section{CONFLICTS OF INTEREST}

No potential conflict of interest relevant to this article was reported.

\section{ORCID}

Jung Suk Sim https://orcid.org/0000-0001-6803-3544

Jung Hwan Baek https://orcid.org/0000-0003-0480-4754

\section{REFERENCES}

1. Sim JS, Baek JH. Long-term outcomes following thermal ablation of benign thyroid nodules as an alternative to surgery: the importance of controlling regrowth. Endocrinol Metab (Seoul) 2019;34:117-23.

2. Kim JH, Baek JH, Lim HK, Ahn HS, Baek SM, Choi YJ, et al. 2017 Thyroid radiofrequency ablation guideline: Korean Society of Thyroid Radiology. Korean J Radiol 2018;19:63255.

3. Jung CK, Baek JH. Recent advances in core needle biopsy for thyroid nodules. Endocrinol Metab (Seoul) 2017;32:40712.

4. Ha SM, Shin JY, Baek JH, Song DE, Chung SR, Choi YJ, et al. Does radiofrequency ablation induce neoplastic changes in benign thyroid nodules: a preliminary study. Endocrinol Metab (Seoul) 2019;34:169-78.

5. Dobrinja C, Bernardi S, Fabris B, Eramo R, Makovac P, Bazzocchi G, et al. Surgical and pathological changes after radiofrequency ablation of thyroid nodules. Int J Endocrinol 2015;2015:576576.

6. Kim M, Chung SR, Jeon M, Han M, Lee JH, Song DE, et al. Determining whether tumor volume doubling time and growth rate can predict malignancy after delayed diagnostic surgery of follicular neoplasms. Thyroid 2019 Aug 2 [Epub]. https://doi.org/10.1089/thy.2019.0017. 